\title{
Crustal structure of Australia from ambient seismic noise tomography
}

\author{
Erdinc Saygin $^{1}$ and B. L. N. Kennett ${ }^{1}$ \\ Received 29 March 2011; revised 28 October 2011; accepted 1 November 2011; published 7 January 2012.
}

[1] Surface wave tomography for Australian crustal structure has been carried out using group velocity measurements in the period range 1-32 s extracted from stacked correlations of ambient noise between station pairs. Both Rayleigh wave and Love wave group velocity maps are constructed for each period using the vertical and transverse component of the Green's function estimates from the ambient noise. The full suite of portable broadband deployments and permanent stations on the continent have been used with over 250 stations in all and up to 7500 paths. The permanent stations provide a useful link between the various shorter-term portable deployments. At each period the group velocity maps are constructed with a fully nonlinear tomographic inversion exploiting a subspace technique and the Fast Marching Method for wavefront tracking. For Rayleigh waves the continental coverage is good enough to allow the construction of a 3D shear wavespeed model in a two stage approach. Local group dispersion information is collated for a distribution of points across the continent and inverted for a $1 \mathrm{D} \mathrm{SV}$ wavespeed profile using a Neighbourhood Algorithm method. The resulting set of 1D models are then interpolated to produce the final $3 \mathrm{D}$ wavespeed model. The group velocity maps show the strong influence of thick sediments at shorter periods, and distinct fast zones associated with cratonic regions. Below the sediments the 3D shear wavespeed model displays significant heterogeneity with only moderate correlation with surface tectonic features. For example, there is no evident expression of the Tasman Line marking the eastern edge of Precambrian outcrop. The large number of available inter-station paths extracted from the ambient noise analysis provide detailed shear wavespeed information for crustal structure across the Australian continent for the first time, including regions where there was no prior sampling because of difficult logistics.

Citation: Saygin, E., and B. L. N. Kennett (2012), Crustal structure of Australia from ambient seismic noise tomography, J. Geophys. Res., 117, B01304, doi:10.1029/2011JB008403.

\section{Introduction}

[2] Estimates of the Green's function between two seismic stations can be extracted from stacks of the cross-correlation of the ambient seismic noise field at the stations. The surface wave portion of the Green's function is large enough to emerge readily as sufficient cross-correlation segments are stacked. The surface wave response corresponding to excitation at one station as recorded at the other can be used in a number of ways in tomographic studies for analyzing the Earth. The dispersive character of the surface waves over a range of periods carries information from different depths that enable recovery of structure through the crust. We exploit over 250 broadband stations, both portable stations deployed over the last 19 years by the Research School of Earth Sciences, The Australian National University, and

\footnotetext{
${ }^{1}$ Research School of Earth Sciences, Australian National University, Canberra, ACT, Australia.

Copyright 2012 by the American Geophysical Union. 0148-0227/12/2011JB008403
}

permanent stations from the recently augmented national network operated by Geoscience Australia.

[3] Previous work on ambient noise tomography for the Australian continent has been carried out by Saygin and Kennett [2010] who worked with just vertical component records and so extracted the Rayleigh wave component of the inter-station Green's functions. In this work we extend the path coverage results by employing stations which have been deployed since 2006, and incorporate Love waves extracted from the correlation of the transverse components of all available seismic stations. We construct group velocity maps in the period rage 1-32 s, and then undertake local inversions of the dispersion properties to extract 1D shear wavespeed profiles. The suite of 1D models are then used to build 3D crustal shear velocity models for the Australian continent. Extension to longer periods in Australia proves to be difficult due to the low signal to noise ratio in the retrieved transfer functions.

[4] The use of the cross-correlation of the ambient seismic noise to obtain Green's function estimates is a relatively new technique. The process was first conjectured by Claerbout 
[1968] in the context of reflection seismology. The first application to studying structure was undertaken by Duvall et al. [1993] for the Sun. The first successful demonstrations for terrestrial broadband seismology were made by Shapiro and Campillo [2004] and Shapiro et al. [2005] to image structure in California. Subsequently, a number of studies have been undertaken for different regions. Some examples are from the United States [Sabra et al., 2005; Shapiro et al., 2005; Bensen et al., 2007; Lin et al., 2008; Bensen et al., 2009; Moschetti et al., 2010], S. Korea [Kang and Shin, 2006], Australia [Saygin and Kennett, 2010; Arroucau et al., 2010], and Europe [Yang et al., 2007; Stehly et al., 2009; Villaseñor et al., 2007].

[5] In general, the dispersion behavior of the group velocity of the surface waves has been used as a means of studying the Earth at depth, using the Green's functions extracted from the ambient noise analysis. The group velocity represents the speed of passage of energy at a particular period. By applying a number of narrow band filters on the extracted wavelet, it is possible to estimate the group wavespeed at different periods. Recently, a number of studies (e.g., those by Yao et al. [2006], Lin et al. [2008], Bensen et al. [2009], and Moschetti et al. [2010]) have incorporated phase velocity information. The interpretation of the phase velocity dispersion, for a particular wave type, is somewhat easier than that for group velocity dispersion. However, it is often not trivial to estimate consistent phase velocities due to the oscillatory nature of the phase spectrum, difficulties in the estimation of the initial phase term, and the topology of seismic networks. Yao et al. [2006] suggested the use of an image processing based algorithm to overcome phase unwrapping problems. Lin et al. [2008] used a triple station solution to find an estimate to correct the far field term for the stations of the Transportable component of the US Array.

[6] Imaging using group velocity has generally been based on constructing $2 \mathrm{D}$ group velocity maps for the study region at different periods. It is then possible to image the 3D structure in a two-step approach. Brenguier et al. [2007] successfully imaged the magma chamber of Piton de la Fournaise volcano by first inverting for 2D group velocity structure, and then using a local linearized shear wave velocity inversion. Stehly et al. [2009] created a Moho map for part of Europe by inverting dispersion measurements from ambient-noise tomographic images. Recent work from Behr et al. [2010] analyzed the shear wave structure of $\mathrm{N}$. Zealand from the phase and group velocity dispersion curves extracted from a number station pairs. Moschetti et al. [2010] inverted Rayleigh and Love group and phase velocities extracted from ambient noise correlations to estimate crustal extension and anisotropy in USA.

[7] In this study, we use all of the available 3-component broadband data from temporary and permanent stations across Australia to extract Green's functions from the ambient seismic noise field. Then we create a number of tomographic maps for group velocity for the periods between $1 \mathrm{~s}$ and $32 \mathrm{~s}$ from the inversions of the passage times for Rayleigh and Love waves. As a final step, we merge the results by estimating the $1 \mathrm{D}$ shear wave velocity structure in the crust, at a set of stations across the continent, with a nonlinear direct-search inversion algorithm from Rayleigh wave group dispersion. The results are then compared with a recently compiled Moho map for the Australian continent [Kennett et al., 2011], which exploits a broad range of seismological information, notably seismic refraction experiments, reflection profiles and receiver function studies.

\subsection{The Nature of the Australian Continent}

[8] The Australian continent is an amalgamation of various tectonic blocks. The western part of the continent contains some of the oldest formations on the Earth. The older part of the continent comprises three Precambrian cratons, the west Australian Craton, the north Australian craton, and south Australian craton [Myers et al., 1996; Betts et al., 2002; Cawood and Korsch, 2008]. In the west Australian craton, the Pilbara and Yilgarn Blocks are well exposed Archean units; detrital zircons from the Narryer domain in the Yilgarn Craton date back as far as $4.3 \mathrm{Ga}$ [Mojzsis et al., 2001]. The orogenesis that occurred between ca. 1790 and 1600 Ma developed the belt that extended from West Australian Craton to the Archean Nucleus of the Gawler Craton in South Australia [Betts and Giles, 2006].

[9] The northern and southern Australian cratons in the middle of the continent are probably the result of the fusion of Proterozoic and Archean units [Myers et al., 1996; Betts et al., 2002; Betts and Giles, 2006]. Recent findings from geochronology [Fraser et al., 2010] show that the Southern Craton is much older than was originally conceived, with ages of 3150 Ma for rocks from the east of the Gawler Craton. The north and south Australian Cratons are characterized by high heat anomalies well above the global average, which also reflects the high radiogenic content of the Proterozoic granites [Wyborn et al., 1992; McLaren et al., 2003, 2005; Cawood and Korsch, 2008].

[10] The eastern part of the continent is mainly Phanerozoic. The Tasman Line originally defined by Hill [1951] defines the transition from Phanerozoic terranes in the east to Precambrian outcrop. A number of definitions of the Tasman Line has been given by various studies by using field observations and geophysical data [e.g., Shaw et al., 1996; Gunn et al., 1997; Scheibner and Veevers, 2000; Direen and Crawford, 2003; Kennett et al., 2004]. However, seismic studies have not found a well defined crustal transition zone [Collins, 1991; Clitheroe et al., 2000].

\subsection{Previous Structural Studies}

[11] Studies of the seismic structure of the Australian Continent have a long history. Early surface wave based observations were made by a number of studies. Bolt [1957] reported the propagation characteristics of $\mathrm{Rg}$ and $\mathrm{Lg}$ waves across the continent from the analysis of regional earthquakes. Bolt and Niazi [1964] also described the dispersion of Rayleigh waves across the Australian continent from phase and group velocity measurements for a number of continental paths.

[12] Body waves were used from nuclear explosions conducted on the Australian continent. Bolt et al. [1958] determined the crustal structure from the propagation paths of the body waves to a set of seismic stations. Cleary [1967] found faster body wavespeeds in the shield areas and slow wavespeeds in the recently uplifted areas by analyzing distant nuclear explosions. 
[13] More recently, with the introduction of broadband seismic stations, a number of large-scale seismic deployments have been carried out across Australia. The Skippy array was the first of this kind of deployment [van der Hilst et al., 1994]. From the early phases of Skippy, Zielhuis and van der Hilst [1996] demonstrated the strong shear wavespeed contrast between old shield regions and eastern Australia. Simons et al. [1999, 2002] showed the complex nature of the transition from Precambrian Australia to the Phanerozoic Australia by using surface wave tomography. Debayle and Kennett [2000a, 2000b] confirmed the complex transition in the upper mantle with significant $S_{V}$ wave azimuthal anisotropy in the $250 \mathrm{~km}$ of the upper mantle, and evidence for radial anisotropy. Yoshizawa and Kennett [2004] introduced a 3-stage approach for the inversion of multi-model surface waves for the Australian continent that takes account of finite frequency effects and deviations from great-circle paths. Fishwick et al. [2005, 2008] used multiple starting models to ensure the reliability of the shear wave speed models from the surface wave tomography; Fishwick et al. [2008] showed a series of steps in the lithospheric thickness of eastern Australia from the results of surface wave tomography.

[14] The crustal thickness in Australia was studied by Clitheroe et al. [2000] by compiling estimates from seismic reflection, refraction and receiver function studies, and endeavored to characterize the nature of Moho transition as thin, broad or sharp. Following dense seismic station deployments in Western Australia, Reading and Kennett [2003] and Reading et al. [2003b, 2007] studied the crust and upper mantle structure of Archean cratons in detail. The crust to mantle transition is found to be gradational near the proposed terrane boundaries and sharper inside the terranes themselves.

[15] Anisotropy in the Australian continent has been studied from the analysis of the broadband records collected from the temporary deployments and permanent stations. Using shear wave splitting measurements for SKS and related phases, Heintz and Kennett [2005, 2006] found an apparently isotropic continent. The directions of fast propagation, where splitting was observed, did not show any direct correlation with the transition between Precambrian and Phanerozoic Australia.

[16] Fichtner et al. [2009] used full waveform adjoint tomography with full allowance for 3D structure and confirmed low $\mathrm{S}$ wavespeeds in the upper mantle below $120 \mathrm{~km}$ beneath eastern Australia, contrasting with high S wavespeeds to more than $200 \mathrm{~km}$ in the center and west of the continent. A later study by Fichtner et al. [2010] used a combination of adjoint and spectral element methods to image the Australian upper-mantle with allowance for radial anisotropy. The results indicate a clear radial anisotropy with a ocean-continental dichotomy above $150 \mathrm{~km}$ with consistent $V_{S H}>V_{S V}$ in the oceans, and a weaker and variable anisotropy beneath continental Australia.

\section{Data}

[17] Portable broadband deployments in Australia were started by the Australian National University in 1992. From 1992 to date, over 250 broadband stations span the continent to give a high spatial coverage for numerous broadband seismic studies. In addition to these portable stations, we also add data from stations in the IRIS and Geoscience Australia networks which act as tie points since the recording period of these stations are generally longer than individual deployments of portable stations (Figure 1a). The broadband seismic sensors used in the various deployments include Güralp CMG-3 ESP, CMG-40T and Streckeisen STS-1 and STS-2.

\section{Methodology for Ambient Noise Processing}

[18] A detailed discussion of cross-correlation processing for ambient seismic noise is given by Bensen et al. [2007]. Our processing scheme is similar to this approach. However, rather than using the conventional cross-correlation between stations, we have used the transfer function that has the same phase response but a broader frequency response [Saygin and Kennett, 2010, Appendix B]. This transfer-function approach for estimating the Green's functions is implemented in the frequency domain with a water-level type deconvolution [Helmberger and Wiggins, 1971] controlled by a parameter (c) that acts as a spectral whitening operator. In terms of the Fourier transforms of the recorded seismic velocity field at the stations $A$ and $B, \mathbf{v}\left(\mathbf{x}_{\mathbf{A}}, \omega\right)$ and $\mathbf{v}\left(\mathbf{x}_{\mathbf{B}}, \omega\right)$ :

$$
\boldsymbol{\Phi}(\omega)=\frac{\mathbf{v}\left(\mathbf{x}_{\mathbf{A}}, \omega\right) \mathbf{v}^{*}\left(\mathbf{x}_{\mathbf{B}}, \omega\right)}{\varphi_{\mathbf{s s}}(\omega)},
$$

where * denotes the complex conjugate. The denominator is regularized by the water level parameter $\mathbf{c}$,

$$
\varphi_{\mathbf{s s}}(\omega)=\max \left[\varphi_{1}, \varphi_{2}\right]
$$

with

$$
\begin{gathered}
\varphi_{1}=\mathbf{v}\left(\mathbf{x}_{\mathbf{B}}, \omega\right) \mathbf{v}^{*}\left(\mathbf{x}_{\mathbf{B}}, \omega\right) \\
\varphi_{2}=\mathbf{c} \max \left[\mathbf{v}\left(\mathbf{x}_{\mathbf{B}}, \omega\right) \mathbf{v}^{*}\left(\mathbf{x}_{\mathbf{B}}, \omega\right)\right] .
\end{gathered}
$$

The presence of the waterlevel term sets a floor to the minimum value of the denominator, and so suppresses large spectral excursions in the transfer function. Unlike the crosscorrelation, the transfer function is not modulated by the square of the ambient-noise spectrum and hence has a much broader spectral response (see auxiliary material). ${ }^{1}$

[19] In our calculations, we use a fixed value of 0.01 for the water-level compensation $\mathbf{c}$ in the deconvolution to provide a stable estimate for the transfer functions. For longer periods, the transfer function provides more stable results than for plain cross-correlations (Figure 2).

[20] To ensure the stability of the Green's function estimates, we compute the transfer functions for 4 hour windows with 1 hour overlap. All of the various estimates for the same pair of stations are then stacked and normalized to create the estimate of the stacked Green's function. Rayleigh wave picks are made on the vertical components of Green's functions, but are checked against the radial component as

${ }^{1}$ Auxiliary materials are available in the HTML. doi:10.1029/ $2011 \mathrm{JB} 008403$. 

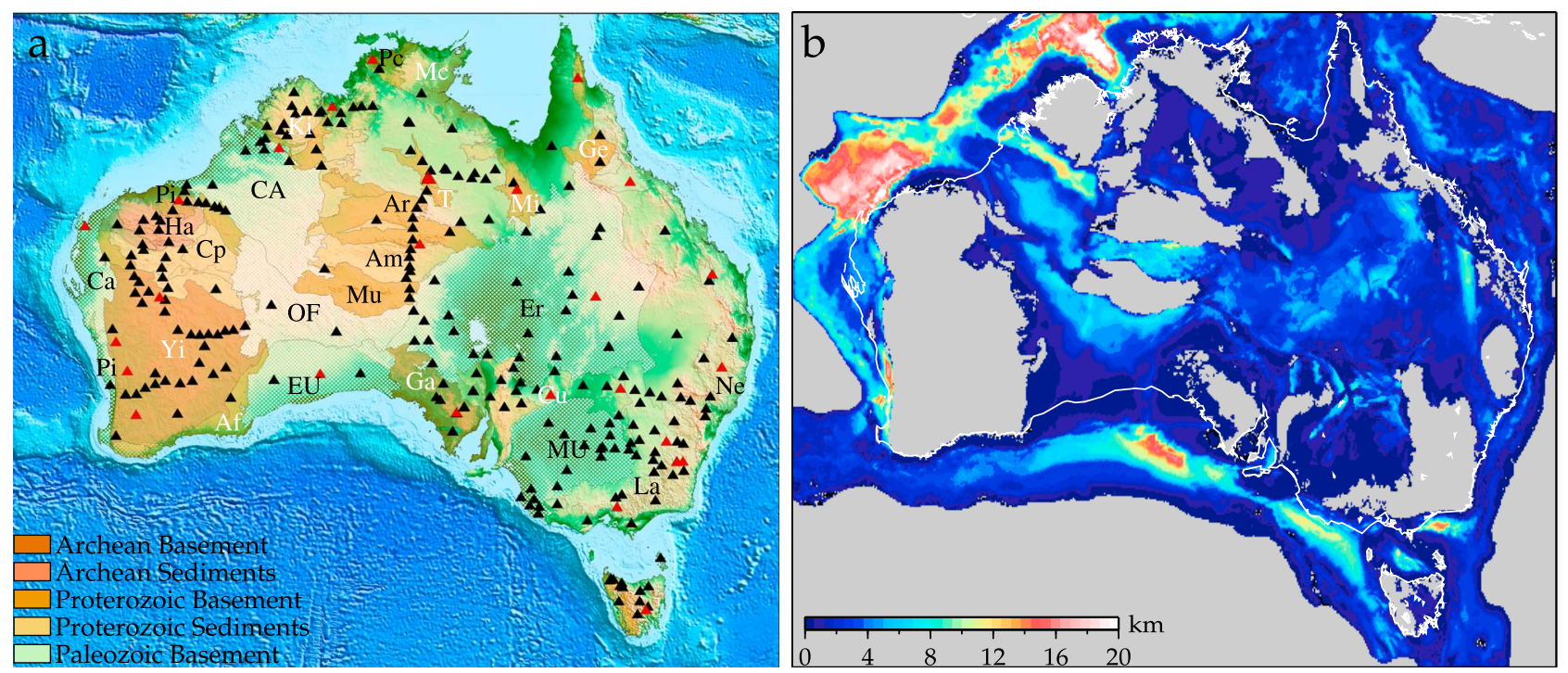

Figure 1. (a) Tectonic provinces of Australia with an overlay of seismic broadband stations used in this study. Black triangles denote stations from temporary deployments. Red triangles show the permanent stations. Some of the major tectonic blocks are as follows: Af, Albany-Fraser Belt; Am, Amadeus Basin; Ar, Arunta Block; Ca, Carnarvon Basin; CA, Canning Basin; Cp, Capricorn Orogeny; $\mathrm{Cu}$, Curnamona Craton; E, Eromanga Basin; EU, Eucla Basin; Ga, Gawler Craton; Ha, Hamersley Basin; Ki, Kimberley Block; Mc, McArthur Basin; Mu, Musgrave Block; MU, Murray Basin; La, Lachlan Orogen; Ne, New England Orogeny; OF, Officer Basin; Pc, Pine Creek Inlier; Pi, Pilbara Craton; Pj, Pinjarra Orogeny; T, Tennant Creek Block; Yi, Yilgarn Craton. (b) Oz Seebase sediment thickness map for Australia (http://www.frogtech.com.au/ozseebase/).

well. By doing this, we ensure that the correct portion of the waveform is picked. Love waves are picked from the transverse component of the Green's functions. We carry out the dispersion analysis on the stacked waveforms by applying the standard procedure of a number of narrow Gaussian filters with center periods in the range from $1 \mathrm{~s}$ to $50 \mathrm{~s}$. We exclude station pairs which are more closely spaced than a wavelength.

[21] The number of available propagation paths across the continent varies with the period range of the dominant ambient seismic noise. The maximum number of paths is achieved for measurements at $4 \mathrm{~s}$ period with over 7500 paths for Rayleigh and over 3800 paths for Love waves. This study improves on the previous work by Saygin and Kennett [2010] by adding data from the recently conducted deployments of portable stations and also the growing Geoscience Australia network of stations for tsunami warning. The improvement in the available path density yields better recovery in areas such as the deserts of central Australia where station deployment is sparse due to complex logistics. In Figure 3, we present Rayleigh and Love wave transfer functions between selected permanent stations and temporary arrays.

\section{Tomographic Inversion}

[22] The tomographic inversion for the spatial structure is carried out using the passage times extracted from the dispersion analysis of the group wavespeed. We use a $1.4^{\circ} \times 1.4^{\circ}$ cellular representation for the tomographic inversion at each period, which gives optimum balance

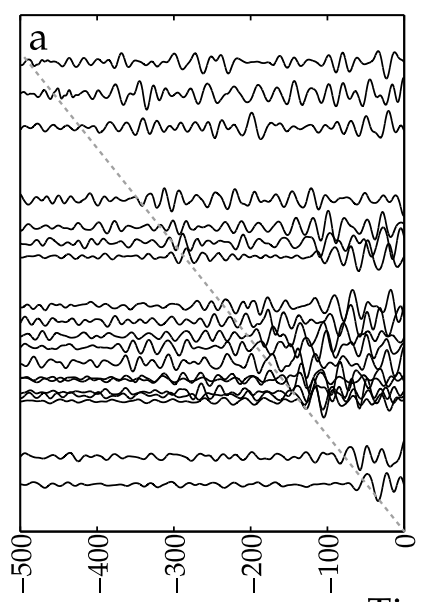

Time (s)

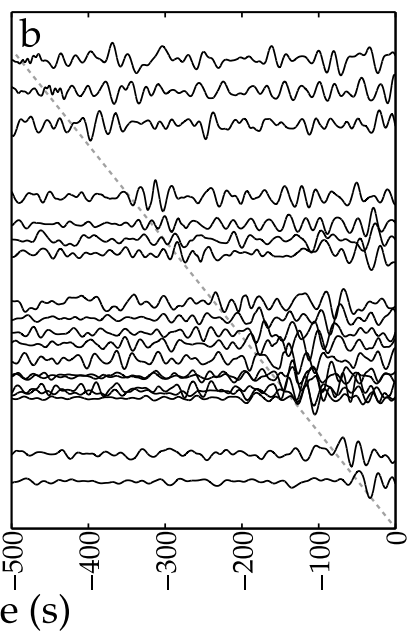

Figure 2. Extracted Rayleigh waves from ambient seismic noise for the stations of the Bilby experiment in central Australia that spans from the southern to the northern Australian craton: (a) cross-correlation method and (b) transfer function method. All traces are filtered with a Butterworth filter of $0.005-0.05 \mathrm{~Hz}$ and traces are normalized to unity. The dashed grey line indicates the arrival times for reference velocity $2.8 \mathrm{~km} / \mathrm{s}$. Notice the difference in amplitude and the frequency contents between the cross-correlation and transfer function methods for the longer inter-station separations. 


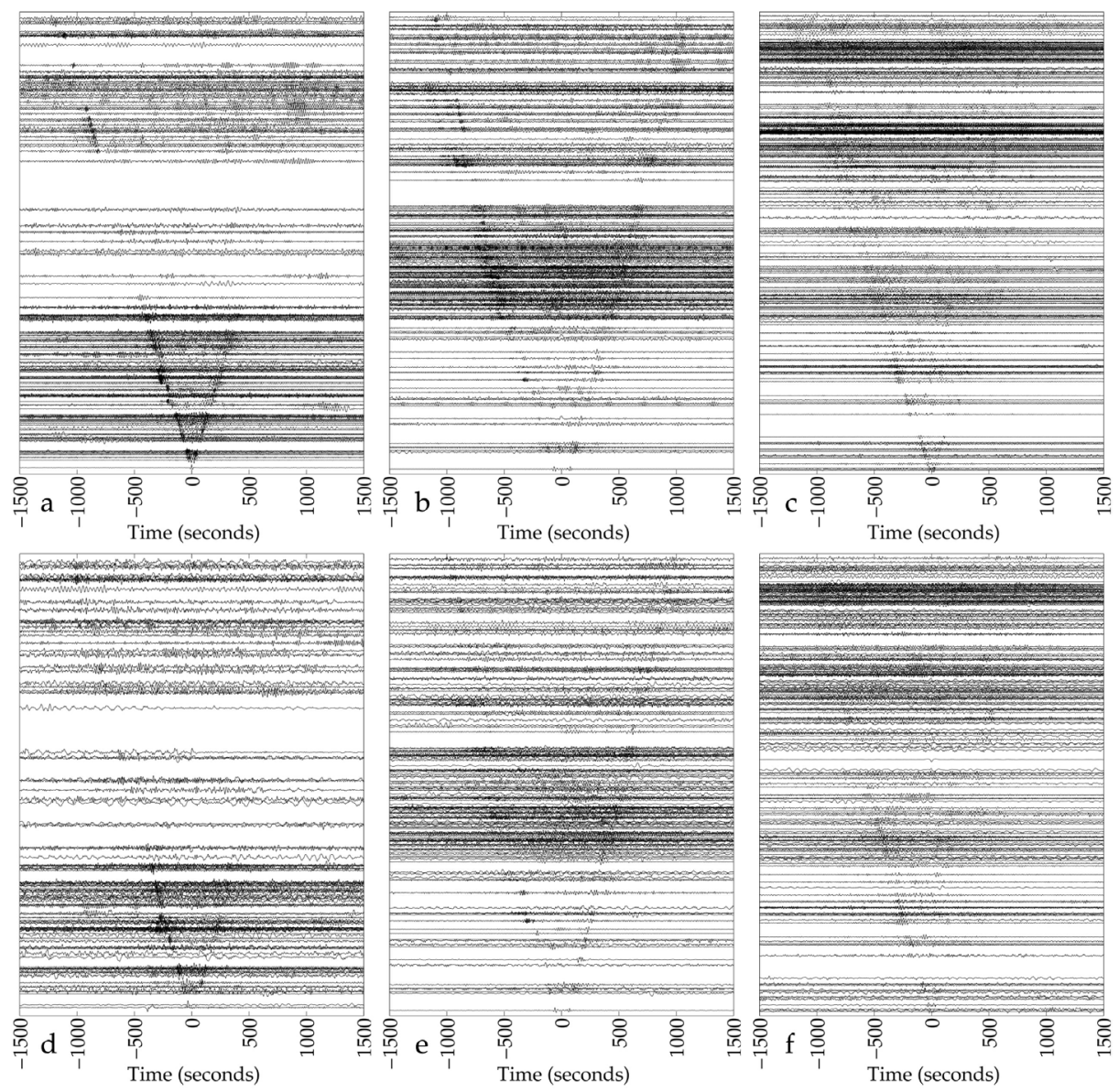

Figure 3. Extracted Rayleigh and Love waves from vertical and transverse components transfer functions of different permanent and temporary arrays. Signals were filtered with $0.01-0.08 \mathrm{~Hz}$ Butterworth filter and normalized to unity. Rayleigh wave: (a) CAN-G, (b) CTAO-IU, and (c) TAU-II. Love wave: (d) CAN-G, (e) CTAO-IU, and (f) TAU-II.

between resolution and recovery. We adapt the inversion strategy of Rawlinson and Sambridge [2004] to work with the surface wave propagation incorporating 2D wavetracking at each period. We use the Fast Marching Method (FMM) [Sethian and Popovici, 1999; Rawlinson and Sambridge, 2004] to track wavefronts in heterogeneous media, and during the course of the iterative inversion repeatedly update the path connecting the two stations using the fast marching results. By this means we accommodate off-greatcircle propagation between station for longer distances $\left(>20^{\circ}\right)$.

[23] Strictly surface wave tracking should be based on the phase slowness rather than the group slowness. However, we will obtain comparable results if the gradients of the two slownesses have similar geographic patterns. Such correspondence has recently been verified for southeastern Australia by Young et al. [2011]. An empirical confirmation of the suitability of this procedure is that the use of group slowness lead to inversions that match well with known geological features such as the patterns of sedimentary basins derived from the shorter period results.

[24] The tracked passage times between stations are inverted with a subspace approach Kennett et al. [1988], to adjust the model parameters. The subspace method is a nonlinear iterative solver, which operates by projecting the quadratic approximation of objective function of the inversion into a multi-dimensional subspace. The objective function for the tomographic inversion can be expressed as

$$
\begin{aligned}
\Phi(\mathbf{m})= & \left(\mathbf{g}(\mathbf{m})-\mathbf{d}_{\mathbf{o b s}}\right)^{\mathbf{T}} \mathbf{W}_{\mathbf{d}}^{-1}\left(\mathbf{g}(\mathbf{m})-\mathbf{d}_{\mathbf{o b s}}\right) \\
& +\epsilon\left(\mathbf{m}-\mathbf{m}_{0}\right)^{\mathbf{T}} \mathbf{W}_{\mathbf{m}}^{-1}\left(\mathbf{m}-\mathbf{m}_{0}\right)+\eta \mathbf{m}^{\mathbf{T}} \mathbf{D}^{\mathbf{T}} \mathbf{D} \mathbf{m},
\end{aligned}
$$

where $\mathbf{g}(\mathbf{m})$ are the predicted group traveltimes from the model, $\mathbf{d}_{\text {obs }}$ are the observed group traveltimes, $\mathbf{W}_{\mathbf{d}}$ is the data weighting matrix, $\mathbf{m}_{0}$ is the reference model, $\mathbf{W}_{\mathbf{m}}$ is the model parameter covariance matrix, $\mathbf{D}$ is flatness/ smoothness matrix, $\epsilon$ is the damping parameter, and $\eta$ is the smoothing parameter. The perturbation can be written as

$$
\delta \mathbf{m}=-\mathbf{A}\left[\mathbf{A}^{\mathbf{T}} \mathbf{J} \mathbf{A}\right]^{-1} \mathbf{A}^{\mathbf{T}} \hat{\gamma},
$$

with

$$
\mathbf{J}=\left(\mathbf{G}^{\mathbf{T}} \mathbf{W}_{\mathbf{d}}^{-1} \mathbf{G}+\epsilon \mathbf{W}_{\mathbf{m}}^{-1}+\eta \mathbf{D}^{\mathbf{T}} \mathbf{D}\right),
$$




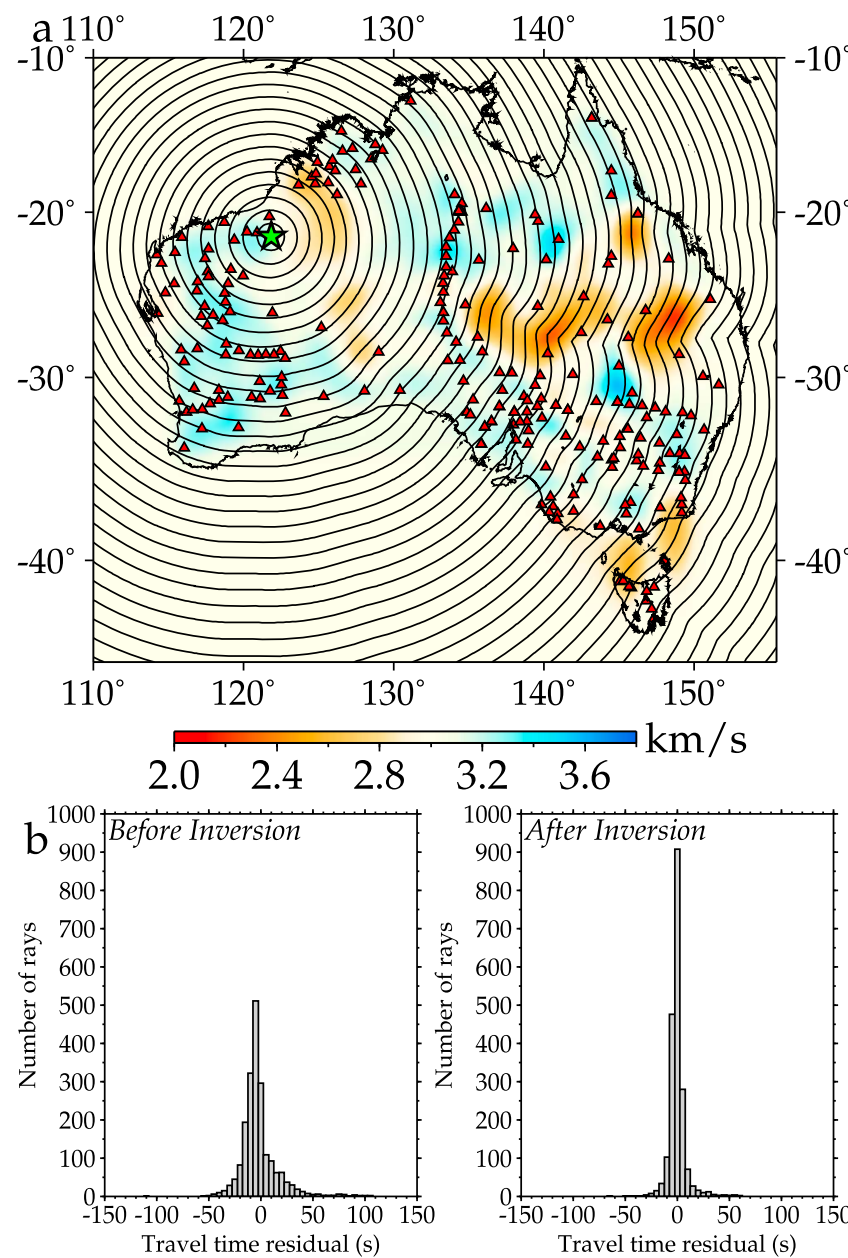

Figure 4. (a) Evolution of the wavefront in the case of strongly heterogeneous media. The station marked with a green star acts as the source, and the red triangles show the receivers in relation to the advancing wavefronts. Note the triplication effects around the low velocity zones. (b) Histograms of passage time residuals for measurements at $10 \mathrm{~s}$ for Rayleigh waves, initially compared to a uniform reference model with velocity of $2.8 \mathrm{~km} / \mathrm{s}$ with great-circle paths, and after the inversion with 6 iterations of the subspace method with deviated paths.

where $\mathbf{A}=\left[\mathbf{a}^{\mathbf{j}}\right]$ is the $M \times n$ projection matrix, $\mathbf{G}$ is the matrix of Fréchet derivatives, $\hat{\gamma}$ is the gradient vector $\left(\gamma=\partial \Phi / \partial \mathbf{m}, \gamma=\mathbf{W}_{\mathbf{m}} \hat{\gamma}\right)$ [Rawlinson and Sambridge, 2003; Kennett et al., 1988]. By estimating the model perturbation, a new model is computed and the wavefronts are then retraced with FMM. Details of the both the wavefront construction and the subspace approach are given by Rawlinson and Sambridge [2004].

[25] In Figure 4a, the wavefront evolution is shown for a source in northwestern Australia for the group wavespeed model at $10 \mathrm{~s}$ period. The bending of the wavefront in the presence of low velocities accurately maps the strong velocity contrasts in the region. In Figure $4 \mathrm{~b}$, the distribution of the residuals between observed and calculated passage times before and after the inversion are shown for measurements taken at $10 \mathrm{~s}$ period, the allowance for path deviation from the great-circle after inversion leads to a much tighter distribution of residuals.

[26] Figures 5 and 6 display the set of group velocity images recovered from the tomographic inversion for a range of periods. The group wavespeed maps are arranged in order of increasing period and hence increasing penetration into the Earth. Each image has an accompanying velocity scale, which moves progressively to higher velocities as the period increases to allow for the dispersion in group speed. For both Rayleigh waves, Figure 5, and Love waves, Figure 6, we see significant contrasts in group wavespeed with some areas of persistently slower group speeds. For each image we show the distribution of paths that control the mapped variations in group velocity.

[27] For Rayleigh waves, very good coverage of the continent is available for medium periods between 8 and $20 \mathrm{~s}$. At shorter periods, the path coverage tends to concentrate to specific deployments in regions with low attenuation such as western and central Australia. Coverage begins to drop off slightly at the longest periods, where we have to rely on relative long paths across the continent (see auxiliary material).

[28] The Love wave coverage is quite good, but it has not proved possible to match the numbers of measurements made for Rayleigh waves. Short period coverage is concentrated in a few areas and at the longer periods coverage is not quite sufficient to get a sufficient density of crossing paths for the whole continent. Nevertheless, the independent estimates of structure from Love wave dispersion help us to assess the validity of the tomograms from the Rayleigh wave component of the Green's functions, once we recognize that, at the same period, Love waves tend to sample slightly shallower parts of the Earth than Rayleigh waves [Kennett, 2001].

\section{Shear Wave Velocity Inversion}

[29] With the suite of group velocity maps for different periods we can extract estimates of the group velocity dispersion for the fundamental modes of Rayleigh and Love waves at suitable points across the continent. The smoothing and damping parameters used in the construction of each of the maps are kept the same to ensure the consistency of the inversion procedure.

[30] We have chosen a set of sampling points (Figure 8a) such that we can achieve a continent wide distribution of locations where we can extract a full dispersion curve for Rayleigh waves. For Love waves we can only get suitable dispersion information in a few patches rather than the whole continent. Thus we invert for an isotropic SV wavespeed model as a function of depth from the local Rayleigh wave group dispersion.

[31] The inversion of the local group wavespeed dispersion curves to generate 1D shear wavespeed profiles is carried out with the Neighbourhood Algorithm [Sambridge, 1999; Wathelet, 2008]. The theoretical dispersion curves used in every inversion step are computed by following the formulation of Dunkin [1965], see Wathelet [2005] for a detailed description.

[32] The neighbourhood algorithm (NA) is a direct search scheme which does not require the presence of a initial model or linearization of the inverse problem. The model sampling is carried out exploiting the geometric constructs 

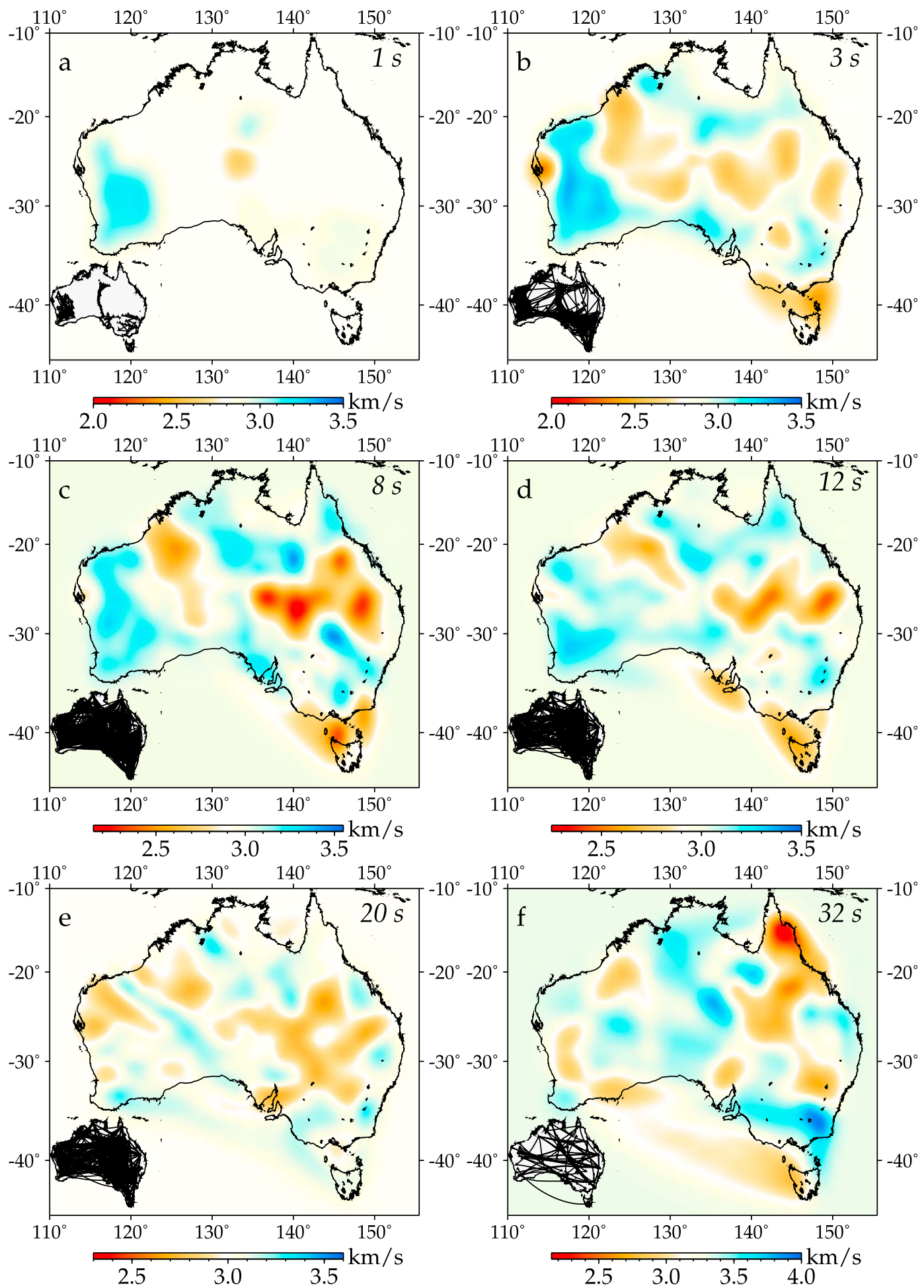

Figure 5. Rayleigh wave group velocity tomography for the period range of 1-32 s created from passage time measurements taken from the Green functions estimates from ambient seismic noise correlations. The distribution of paths from the inversion is shown in the bottom left corner of each tomogram. Periods are (a) $1 \mathrm{~s}$, (b) $3 \mathrm{~s}$, (c) $8 \mathrm{~s}$, (d) $12 \mathrm{~s}$, (e) $20 \mathrm{~s}$, and (f) $32 \mathrm{~s}$. A separate velocity scale is provided for each panel.

of Voronoi cells, which offers robust sampling of model space. The NA has been used for the inversion of many different classes of geophysical inversion problems [e.g., Kennett et al., 2000; Snoke and Sambridge, 2002; Reading et al., 2003a]. The NA samples the model parameter space in a self adaptive way, evolving towards maximum sampling in regions of model space with good fit to data. This feature is essential to avoid initial model dependency problems, which are often reported in various classes of geophysical data inversions [e.g., Ammon et al., 1990]. 

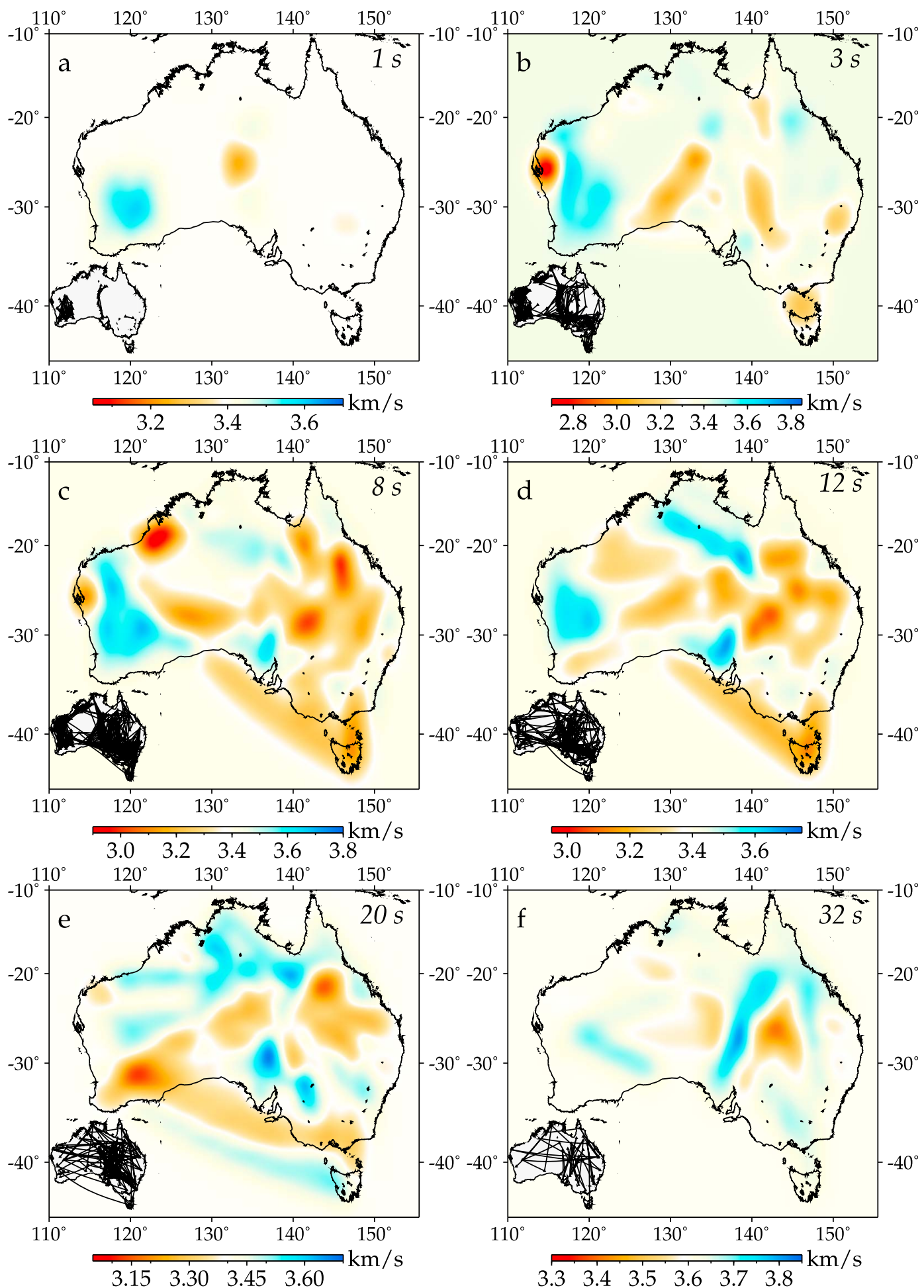

Figure 6. Love wave group velocity tomography for the period range of 1-32 s created from passage time measurements taken from the Green functions estimates from ambient seismic noise correlations. The distribution of paths from the inversion is shown in the bottom left corner of each tomogram. Periods are (a) $1 \mathrm{~s}$, (b) $3 \mathrm{~s}$, (c) $8 \mathrm{~s}$, (d) $12 \mathrm{~s}$, (e) $20 \mathrm{~s}$, and (f) $32 \mathrm{~s}$. A separate velocity scale is provided for each panel.

[33] We use a 5 layer model similar to that employed by Clitheroe et al. [2000] for receiver function inversions of Australian crust (Table 1). The model is inverted for shear wave velocity, and Poisson's ratio along with the layer thicknesses. Rather than seeking a single best-fitting model, we explore the model parameter space by examining the ensemble of models. This approach finds the regions of model parameter space with good data fit [Sambridge, 
Table 1. Parameterization for the Shear Wave Velocity Inversion ${ }^{\mathrm{a}}$

\begin{tabular}{lccc}
\hline & Layer Thickness $(\mathrm{km})$ & Shear Velocity $(\mathrm{km} / \mathrm{s})$ & Poisson's Ratio \\
\hline Sediment layer* & $0.0-2.0$ & $0.5-1.5$ & $0.33-0.43$ \\
Basement layer & $0.0-3.0$ & $1.7-2.7$ & $0.21-0.33$ \\
Upper crust & $5.0-20.0$ & $2.9-3.9$ & $0.21-0.27$ \\
Middle crust & $5.0-20.0$ & $3.4-4.4$ & $0.21-0.27$ \\
Lower crust* & $0.0-15.0$ & $3.7-4.8$ & $0.21-0.27$ \\
Half space & & & \\
\hline
\end{tabular}

${ }^{a}$ The asterisks denote the parameters to which constraints are applied for sedimentary and Moho depths with an absolute $10 \%$ variation.

1999]. We employ a $L_{2}$ measure of fit between observed and calculated group dispersion values.

[34] Woodhouse [1974] has demonstrated that for slowly varying media the local dispersion corresponds to the structure directly beneath a point. However, in zones of rapid change this correspondence can not be assured [Yanovskaya, 1984]. To account for finite frequency effects on the propagation of surface waves, we use the concept of the influence zone derived by Yoshizawa and Kennett [2002]. The influence zone determines the effective sampling of surface waves along the propagation path connecting the source and receiver, with a spatial extent of approximately $1 / 6$ of the first Fresnel Zone for the appropriate period. We extract the group velocities from perturbation map for a chosen point by finding the closest source-receiver path, and then computing the wavefront corresponding the wave propagation. The group velocities are then extracted along the wavefront for the portion bounded by the influence zone. All of the estimates for group velocity at a point are then averaged to at each period, and the averaged velocities used to construct the local dispersion curve for the shear wavespeed inversions.

[35] The 1D velocity inversion for a systematic set of sample points aims to create a shear wave velocity profile to constrain structure from the shallow subsurface to the lower crust of Australian continent. In our inversions, we use two constraints in the inversions: (1) from the recently compilation of Moho depths from various broadband and active seismic reflection and refraction studies [Kennett et al., 2011] and (2) from the Oz Seebase model (http://www. frogtech.com.au/ozseebase/), which maps the sedimentary thickness of the continent. We employ weak depth constraints allowing an absolute variation of $10 \%$ for either sediment thickness or Moho depth at the chosen spatial point. Each inversion is carried out for 1000 iteration steps and at each step we keep the best 50 points in the model space.

[36] At the end of the model search, we select the 5000 models with the best fit to data from the 50000 examined in the course of the inversion. The shear velocity profiles are created by using a weighted average of the 5000 models, penalizing the profiles according to the inverse of the misfit measure. The resulting models are very stable and not dependent on the specific choice of the number of averaged models, e.g., visually identical resultant models are obtained with the best 3000 or just 1000 models. In Figure 7, we show the regionalized group velocity dispersion curves of Rayleigh waves and associated Earth models.

[37] Once the suite of 1D shear wavespeed profiles have been computed for points across the continent, we assemble 3D models by interpolation from the spatial grid shown in Figure $8 \mathrm{a}$. The interpolation is carried out by fitting a surface with a cell size of $0.5^{\circ} \times 0.5^{\circ}$. In Figure 9, horizontal cross sections through the $3 \mathrm{D}$ shear wavespeed model for the whole continent are displayed for a number of depths. Although we have been able to extend our study to considerably longer periods than used by Saygin and Kennett [2010], we still have limited penetration into the mantle and a muted picture of the behavior in the lowermost crust.

\section{Results and Discussion}

\subsection{Group Velocity Tomography}

[38] The tomographic images show complex patterns for the shorter periods, 1-8 s, that sample shallower depths (Figures 5a-5c and 6a-6c) for both Rayleigh and Love wave group wavespeed tomography. The thick sedimentary deposits of the center part of Australia, i.e., the Canning Basin, Eromanga Basin, and Officer Basin are well imaged with lowered group velocities. Cratonic crust shows consistently high group velocities well above the average of $2.8 \mathrm{~km} / \mathrm{s}$. The Archean cratons in Western Australia are notable for their very high group wavespeeds compared to other parts of the continent. The prominent low velocity anomaly in the northwest of Western Australia, which is visible in both Love and Rayleigh wave tomography, corresponds to the Carnarvon Basin in which sediment thickness locally exceeds $8 \mathrm{~km}$. The rapid change in group velocities from the Canning Basin to the Kimberley region (Figures 5b-5d and 6c-6d) marks a major change associated with the Proterozoic King Leopold belt.

[39] In central Australia between longitudes $135^{\circ} \mathrm{E}$ and $140^{\circ} \mathrm{E}$, the presence of high heat gradient as well as crustal composition affects the wavespeed of propagation. Rayleigh wave images show velocities as low as $2.0 \mathrm{~km} / \mathrm{s}$ (Figures 5b-5d). In the Love wave tomograms such anomalies are rather fragmented, largely as a result of the sparse ray path coverage (Figure 6b). For the longer period waves $(20 \mathrm{~s})$, the signature of the sedimentary layers diminishes as the surface waves start to sense the mid to the lower crust. The Arunta and Musgrave blocks show a clear signature in the images separated by a portion of the Officer basin (Figures $5 \mathrm{c}$ and $5 \mathrm{~d}$ ) in the longitude range $125^{\circ} \mathrm{E}-$ $132^{\circ} \mathrm{E}$.

[40] The longer period images mark the complex velocity structure of the continent. The western part has a number of low and high velocity patches, where an indirect comparison can be made with the Moho map (Figure 11c). The relatively shallow Moho depths in the west are reflected in the deeper images that are sensitive to the longer periods of the Rayleigh waves. The alternating pattern of variations of Moho depths in the west is also visible in the Rayleigh wave images (Figures 5e and 5f). However, the full depth extent of 

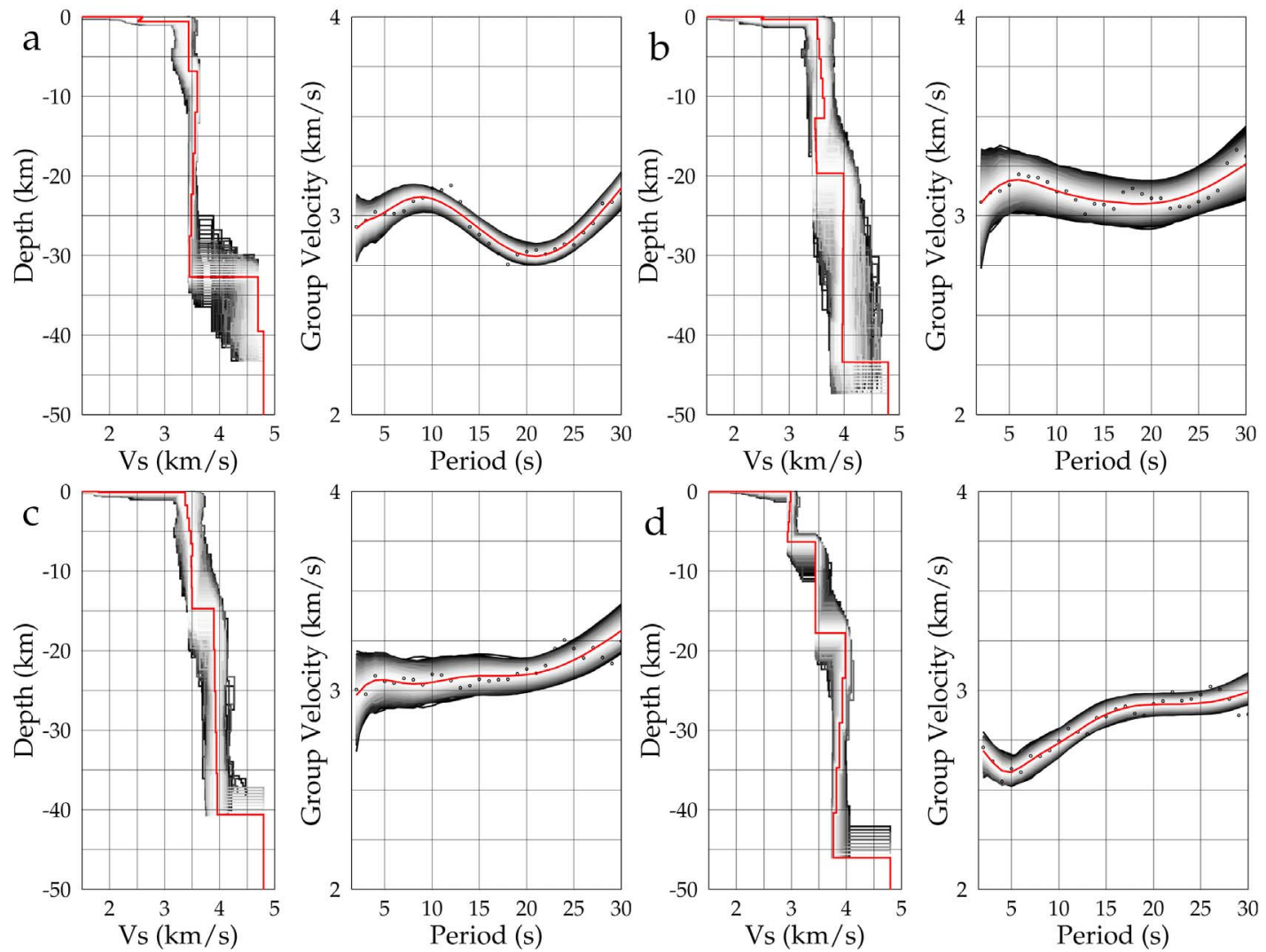

Figure 7. Examples of inverted group velocity dispersion curves of Rayleigh waves from 30000 models. The red curve denotes the average from 5000 best models. Open circles are the measured group velocity at each corresponding period. Lighter colors show the inverted models with lower misfits. (a) Western Australia, (b) North Australia, (c) South Australia, and (d) Eastern Australia.

these anomalies cannot be captured, since the period range of the measurements is insufficient.

[41] The longer period Love wave tomograms show complex velocity variations across the continent. The high velocity anomaly visible in (Figures 6c-6e) marks Gawler craton, which is not clear in the Rayleigh wave images. Although the reduced ray path coverage at higher periods affects the recovery of the anomalies, most of the features such as the low velocity block marking the southern extent of the Yilgarn Block in Western Australia (Figures 6d and 6e) can be followed to shorter periods which have denser ray path coverage. The Mt. Isa block, which is also clearly recovered in Rayleigh wave tomograms, is

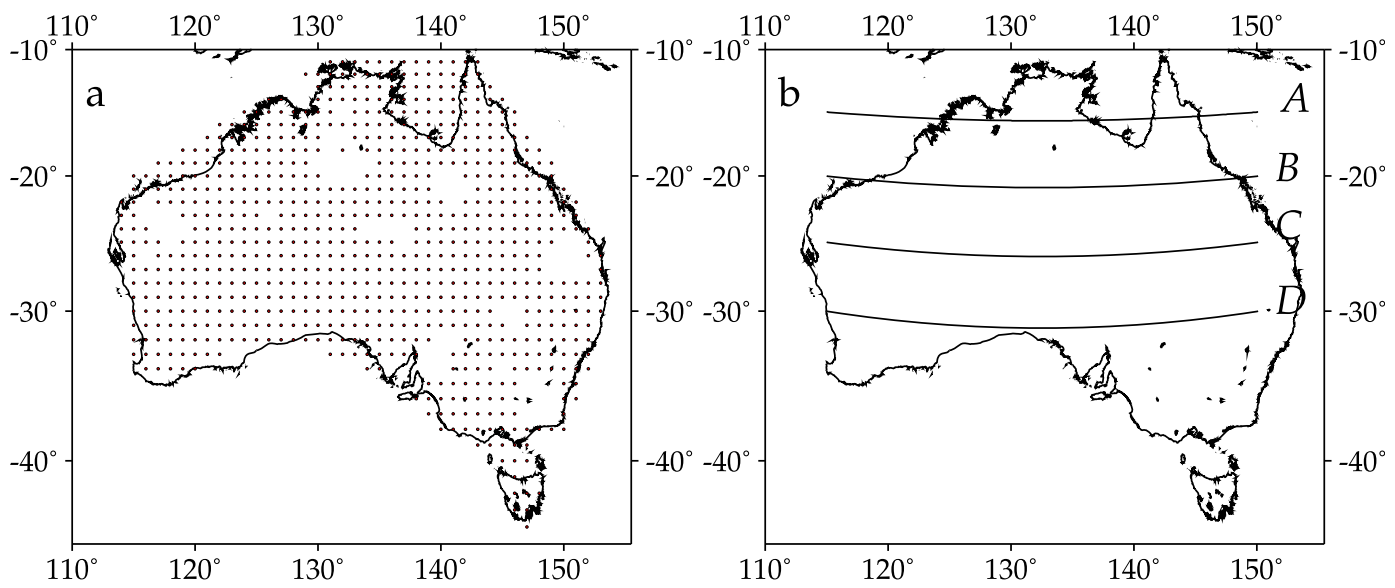

Figure 8. (a) Spatial sampling points used in $1 \mathrm{D}$ inversion. (b) Locations of vertical cross sections A-D displayed in Figure 10. 

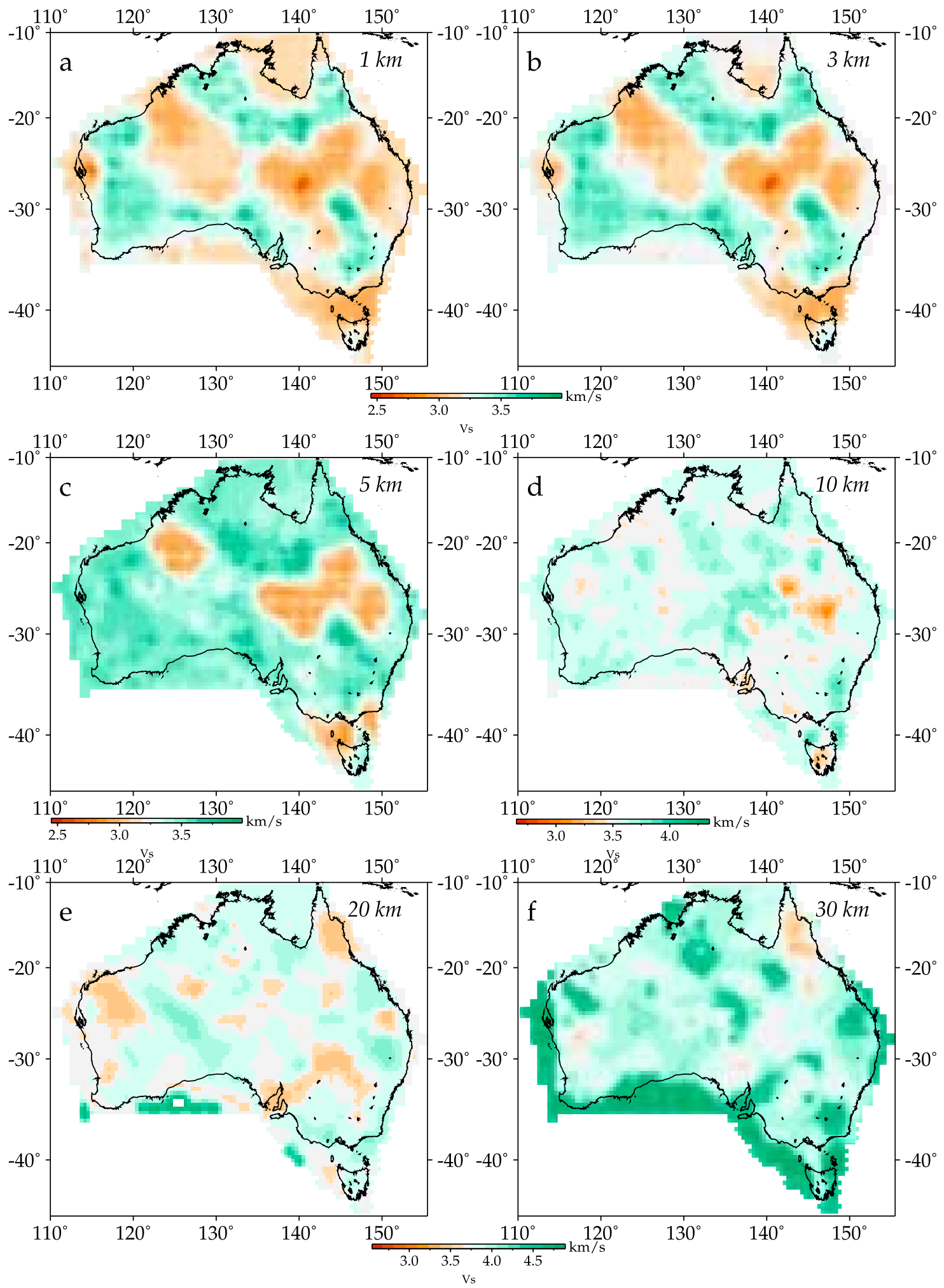

Figure 9. Cross sections through the 3D shear wave velocity model constructed from the set of $1 \mathrm{D}$ inversions that include a weak constraint on depth to Moho. Depths are (a) $1 \mathrm{~km}$, (b) $3 \mathrm{~km}$, (c) $5 \mathrm{~km}$, (d) $10 \mathrm{~km}$, (e) $20 \mathrm{~km}$, and (f) $30 \mathrm{~km}$.

consistently visible in the Love wave images between 8 and $30 \mathrm{~s}$ (Figures 6c-6f).

\subsection{Shear Velocity Inversion}

[42] Although many of the features in the group velocity maps can be associated with surface tectonic features, particularly sediments, the $3 \mathrm{D}$ shear velocity distribution 


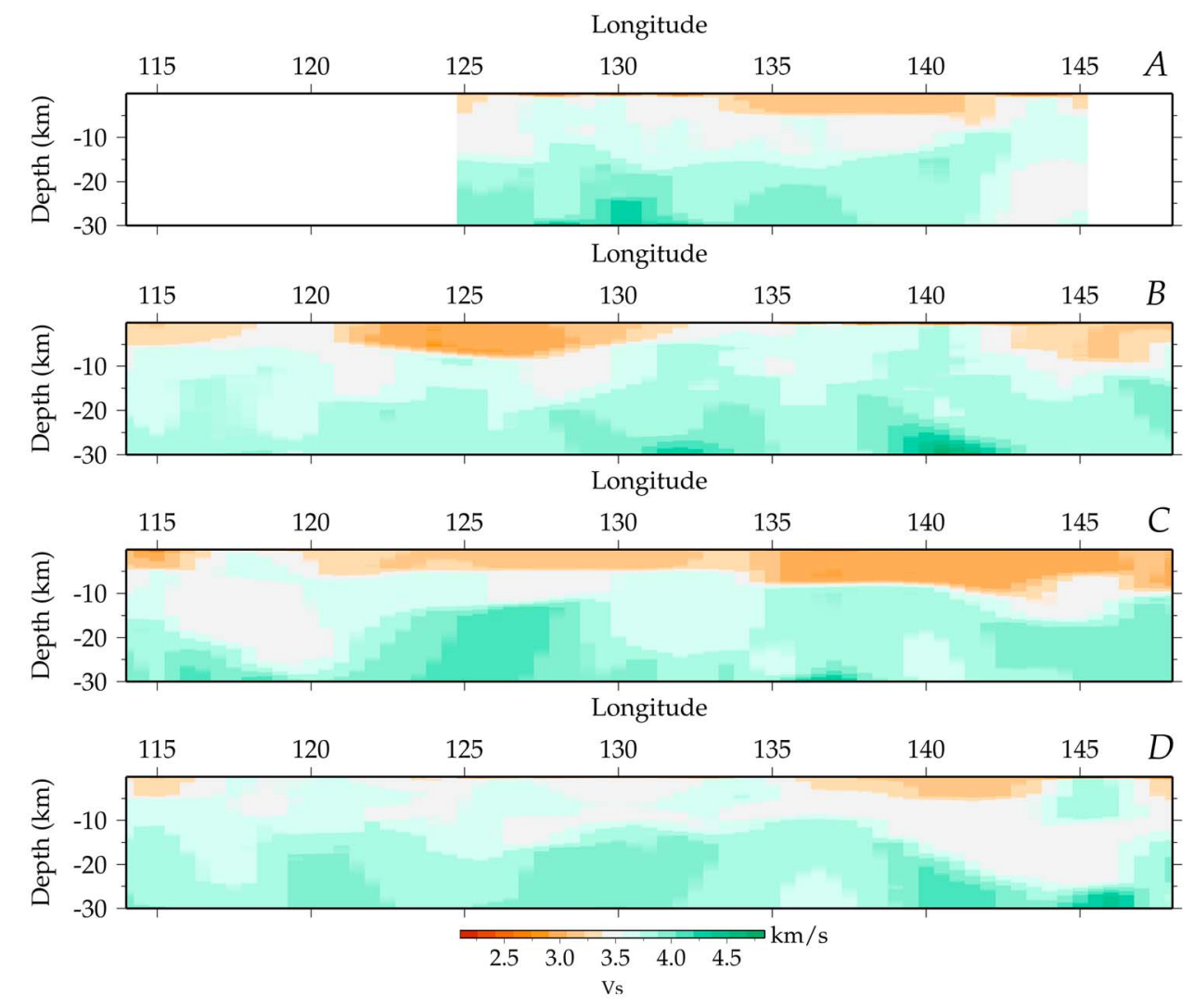

Figure 10. The shear velocity-depth sections along lines A, B, C, and D (Figure 8b). Parts of section A are masked where there is limited tomographic information.

created from the inversion of the Rayleigh wave dispersion curves for larger depths show a less direct relation to surface structure. Overall, the shear velocities increase steadily with increasing depth.

[43] The shear velocity structure at 1,3 , and $5 \mathrm{~km}$ depths (Figures 9a-9c) reflects the influence of the thick sedimentary basins (see Figure 1b) and the shear wavespeeds in these blocks vary between 2.4 and $3.0 \mathrm{~km} / \mathrm{s}$. There is a hint of sedimentary influence at $10 \mathrm{~km}$ depth in eastern Australia, but for most of the continent the shear wavespeed is already quite high, above $3.5 \mathrm{~km} / \mathrm{s}$, though somewhat variable without obvious direct link to surface features. The zone of lowered shear velocities (Figure 9e) located in southeast Australia corresponds to the boundary of the Lachlan Fold Belt in the east. In the west of the continent, the alternating low velocity blocks (Figure 9e) mark the location of the Hamersley Basin and Perth Basin. The deepest image from $30 \mathrm{~km}$ (Figure 9f) show concentrated high velocity patches across the continent, though most of these bodies do not coincide with the known surface features. However, the high velocity body in north Australia $\left(20^{\circ} \mathrm{S}, 140^{\circ} \mathrm{E}\right)$ marks the Mt. Isa block.

[44] Although the range of periods we have extracted does not provide strong control on the transition into mantle velocities, we have examined the extent to which we can determine the thickness of the crust (Figure 10). The Rayleigh wave dispersion should be influenced by the Moho depth if it is less than $40 \mathrm{~km}$, but for greater crustal thickness only the decaying exponential tail of sensitivity will be left, and we should not expect recovery of thick crust.

[45] The vertical cross sections displayed in Figure 10 show mostly the influence of the thick sedimentary cover of Australian continent. In Figure 10, cross section A, from $125^{\circ} \mathrm{E}$, the influence of Kimberley Block is dominant with lowered velocities. Towards the east of the section, a high velocity body exist between $125^{\circ} \mathrm{E}-135^{\circ} \mathrm{E}$, but there is no known link to the surface geology. In Figure 10, cross section $\mathrm{B}$, the Canning Basin penetrates to depths close to $10 \mathrm{~km}$ with a significant lowered velocities. The horizontal extent of this region spans to $130^{\circ} \mathrm{E}$. The high velocities between $130^{\circ} \mathrm{E}$ and $140^{\circ} \mathrm{E}$ marks the presence of the Mt. Isa domain with increased velocities from $25 \mathrm{~km}$. The relatively low velocities to the east of the Mt. Isa block, marks the boundary of the Eromanga basin with depths extending to $10 \mathrm{~km}$. Towards to the south (Figure 10, cross section C), the most prominent feature is the high velocity body located between $115^{\circ} \mathrm{E}$ and $120^{\circ} \mathrm{E}$ that corresponds to the Capricorn Orogeny. However, the true extent of these anomalies can not be resolved due to the lack of measurements at longer periods. The low velocity cover which starts from the eastern extent of the Capricorn Orogeny shows the Officer Basin extending to $135^{\circ} \mathrm{E}$. The change in the low velocity pattern at this location corresponds to the border of the Eromanga Basin. Under the low velocity body at $145^{\circ} \mathrm{E}$, a high velocity feature exists, indicating the northern tip of the Lachlan Fault Belt. Although there is no direct correlation with the surface geology, in general the velocity structure for cross 


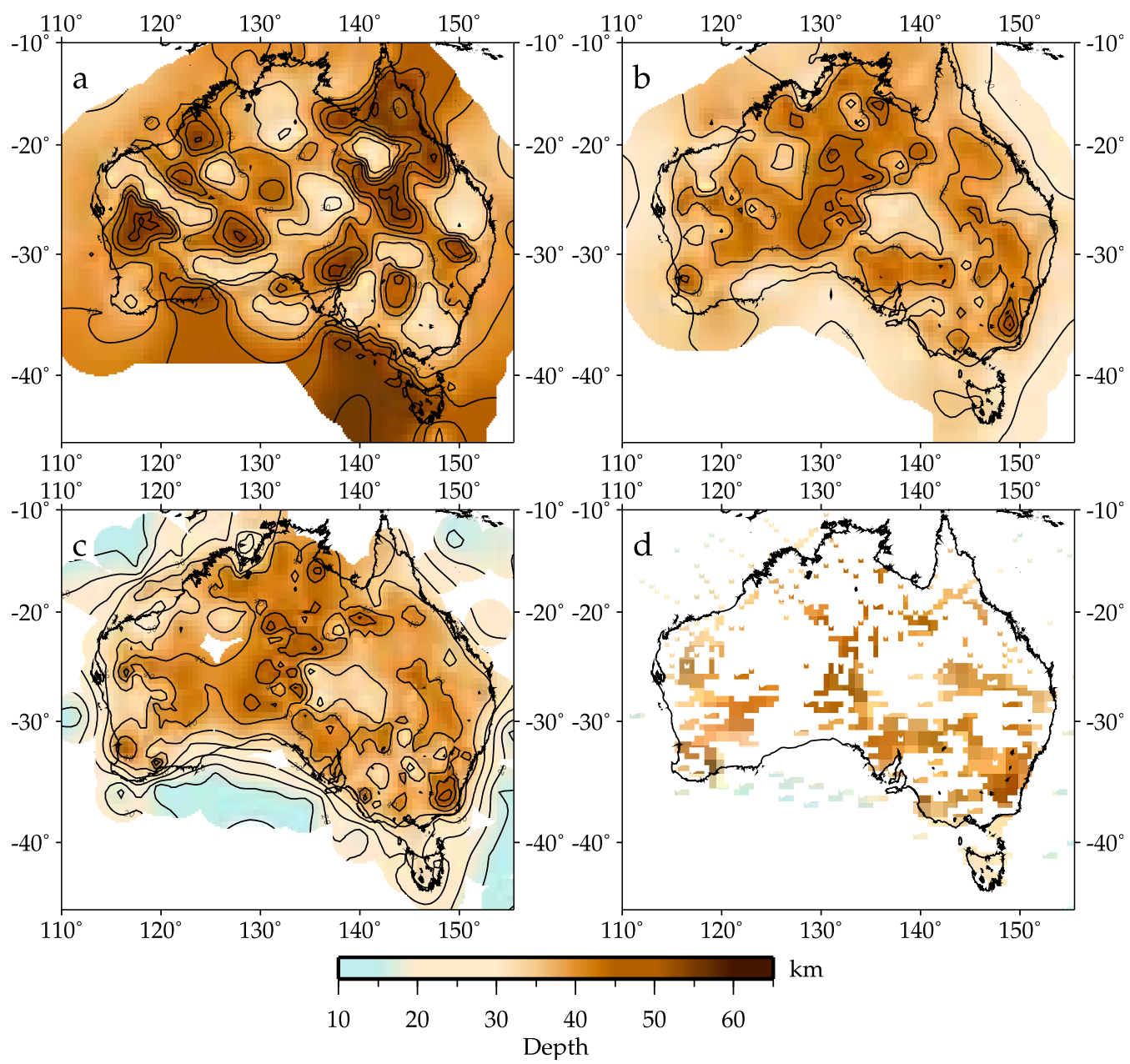

Figure 11. Moho depth images from the inversion of group velocity profiles. (a) Depth inversion without constraints. (b) Depth inversion with constraint of imposed sedimentary and Moho thicknesses with allowed variations of up to $10 \%$. (c) AusMoho model [Kennett et al., 2011]. (d) Location of the crustal thickness estimates used to construct the AusMoho model. A $75 \mathrm{~km}$ rectangle is shown at each point.

section D in Figure 10 shows blocks of isolated high velocity bodies. The terrane change around $135^{\circ} \mathrm{E}$ is reflected with a low velocity anomaly, which marks the Murray Basin.

[46] Overall these vertical cross-section images show complex patterns, with high velocity features that are not readily tied to geological features exposed at the surface. However, this is consistent with the results from surface wave tomography from earthquake data [Fishwick et al., 2005, 2008], where the results are less coherent for shallow depths around $75 \mathrm{~km}$. On the other hand most of the low velocity anomalies that are captured correlate well with the known sedimentary basins in the continent.

[47] In Figure 11, we show the results obtained when we attempt to invert for the depth to Moho using the group velocity dispersion information for Rayleigh waves. If the inversion is unconstrained as in Figure 11a we obtain a highly oscillatory pattern with juxtaposed patches of very thick and relatively thin crust. Since we cannot expect to be able to resolve thick crust we have to be very suspicious of crustal thickness estimates that exceed $50 \mathrm{~km}$. If, however, we introduce a mild constraint on the allowed depth of sediment and Moho by allowing $10 \%$ variation form the values shown in Figure 1b, we find stable results for crustal thickness. The resulting map of the depth to Moho (Figure 11b) has a general pattern that is quite comparable to that in Figure 11c obtained from the analysis of many other types of seismic data [Kennett et al., 2011]. The available sampling of the Moho (Figure 11d) though much improved from earlier studies [e.g., Clitheroe et al., 2000] still has a number of under-sampled zones in areas with difficult access, such as central Western Australia. The new Moho estimates extracted from the ambient noise analysis provide a useful supplement to the other methods.

\section{Conclusion}

[48] By exploiting the correlation properties of ambient seismic noise, continent wide tomographic and shear wave velocity models have been extracted using the full set of portable and permanent broadband stations. The new broadband deployments since the work of Saygin and Kennett [2010], have increased the spatial resolution and the depth ranges extracted from the measurements significantly. 
[49] With the improved coverage of the continent we are able not only to provide a better definition of crustal structure, but also to provide information in areas where previous information has been limited because of logistic difficulties or lack of local earthquakes. The ambient noise technique thus provides a very useful complement to other classes of passive seismological techniques for crustal studies.

[50] The surface wave tomograms for both Rayleigh and Love waves show complex patterns of velocity perturbation, which correspond to the location of known sedimentary basins and high geothermal gradients as well as cratonic blocks. The inversion for 3D shear velocity structure provides new information in many parts of the continent where hitherto there has been localized sampling with receiver functions or $\mathrm{P}$ wave results from refraction experiments. There are evident changes from thick sedimentary zones to deeper and faster blocks, but surface tectonic features have little expression in the distribution of crustal velocities. Thus, e.g., there is no obvious evidence for any wavespeed change associated with the Tasman Line in eastern Australia. Indeed reflection transects across the edge of Precambrian outcrop into the Phanerozoic show little contrast in reflection style, so changes in physical properties can be expected to be small. The surface wave tomography carried out by Fishwick et al. [2008] using earthquake sources concentrates on the mantle component of the lithosphere and shows complex images at $75 \mathrm{~km}$ depth that become much more coherent in the deeper part, i.e., below $150 \mathrm{~km}$.

[51] Acknowledgments. The data collection and analysis has been supported by the Australian National University and the Australian Research Council through ARC Discovery Grants. We thank two anonymous reviewers for their constructive criticism on the manuscript. We also thank the personnel at Seismology Group of RSES for their contributions to the field work. The ObsPy package was used for data format conversions, and Generic Mapping Tools program was used in the preparation of figures (except Figures 2 and 3). Sara Pozgay is thanked for her contribution to the filtering, and waveform picking of the transfer functions. The broadband seismic data for permanent stations have been obtained from IRIS.

\section{References}

Ammon, C. J., G. E. Randall, and G. Zandt (1990), On the nonuniqueness of receiver function inversions, J. Geophys. Res., 95(B10), 15,303-15,318.

Arroucau, P., N. Rawlinson, and M. Sambridge (2010), New insight into Cainozoic sedimentary basins and Palaeozoic suture zones in southeast Australia from ambient noise surface wave tomography, Geophys. Res. Lett., 37, L07303, doi:10.1029/2009GL041974.

Behr, Y., J. Townend, S. Bannister, and M. K. Savage (2010), Shear velocity structure of the Northland Peninsula, New Zealand, inferred from ambient noise correlations, J. Geophys. Res., 115, B05309, doi:10.1029/ 2009JB006737.

Bensen, G. D., M. H. Ritzwoller, M. P. Barmin, A. L. Levshin, F. Lin, M. P. Moschetti, N. M. Shapiro, and Y. Yang (2007), Processing seismic ambient noise data to obtain reliable broad-band surface wave dispersion measurements, Geophys. J. Int., 169, 1239-1260.

Bensen G. D., M. H. Ritzwoller, and Y. Yang (2009), A 3D shear velocity model of the crust and uppermost mantle beneath the United States from ambient seismic noise, Geophys. J. Int., 177(3), 1177-1196.

Betts, P. G., and D. Giles (2006), The 1800-1100 Ma tectonic evolution of Australia, Precambrian Res., 144, 92-125.

Betts, P. G., D. Giles, G. S. Lister, and L. R. Frick (2002), Evolution of the Australian lithosphere, Aust. J. Earth Sci., 49, 661-695, doi:10.1046/ j.1440-0952.2002.00948.x.

Bolt, B. A. (1957), Velocity of the seismic waves $\mathrm{Lg}$ and $\mathrm{Rg}$ across Australia, Nature, 180, 495.

Bolt, B. A., and M. Niazi (1964), Dispersion of Rayleigh waves across Australia, Geophys. J. R. Astron. Soc., 9, 21-35.

Bolt, B. A., H. A. Doyle, and D. J. Sutton (1958), Seismic observations from the 1956 atomic explosions in Australia, Geophys. J. R. Astron. Soc., 1, 135-145.
Brenguier, F., N. M. Shapiro, M. Campillo, A. Nercessian, and V. Ferrazzini (2007), 3-D surface wave tomography of the Piton de la Fournaise volcano using seismic noise correlations, Geophys. Res. Lett., 34, L02305, doi:10.1029/2006GL028586.

Cawood, P. A., and R. J. Korsch (2008), Assembling Australia: Proterozoic building of a continent, Precambrian Res., 166, 1-35, doi:10.1016/j. precamres.2008.08.006.

Claerbout, J. F. (1968), Synthesis of a layered medium from its acoustic transmission response, Geophysics, 33(2), 264-269.

Cleary, J. (1967), P times to Australian stations from nuclear explosions, Bull. Seismol. Soc. Am., 57, 773-781.

Clitheroe, G., O. Gudmundsson, and B. L. N. Kennett (2000), The crustal thickness of Australia, J. Geophys. Res., 105, 13,697-13,713.

Collins, C. D. N. (1991), The nature of the crust-mantle boundary under Australia from seismic evidence, in The Australian Lithosphere, edited by B. Drummond, Geol. Soc. Aust. Spec. Publ., 17, 67-80.

Debayle, E., and B. L. N. Kennett (2000a), The Australian continental upper mantle: Structure and deformation inferred from surface waves, J. Geophys. Res., 105(B11), 25,423-25,450, doi:10.1029/2000JB900212.

Debayle, E., and B. L. N. Kennett (2000b), Anisotropy in the Australian upper mantle from Love and Rayleigh waveform inversion, Earth Planet. Sci. Lett., 184, 339-351.

Direen, N. G., and A. J. Crawford (2003), The Tasman Line: Where is it, what is it, and is it Australia's Rodinian breakup boundary?, Aust. $J$. Earth Sci., 50, 491-502.

Dunkin, J. W. (1965), Computation of modal solutions in layered, elastic media at high frequencies, Bull. Seismol. Soc. Am., 55(2), 335-358.

Duvall, T. L., S. M. Jefferies, J. M. Harvey, and M. A. Pomerantz (1993), Time-distance helioseismology, Nature, 362, 430-432.

Fichtner, A., B. L. N. Kennett, H. Igel, and H.-P. Bunge (2009), Full seismic waveform tomography for upper-mantle structure in the Australasian region using adjoint methods, Geophys J. Int., 179(3), 1703-1725.

Fichtner, A., B. L. N. Kennett, H. Igel, and H.-P. Bunge (2010), Full waveform tomography for radially anisotropic structure: New insights into present and past states of the Australasian upper mantle, Earth Planet. Sci. Lett., 290, 270-280.

Fishwick, S., B. L. N. Kennett, and A. M. Reading (2005), Contrasts in lithospheric structure within the Australian Craton: Insights from surface wave tomography, Earth Planet. Sci. Lett., 231, 163-176.

Fishwick, S., M. Heintz, B. L. N. Kennett, A. M. Reading, and K. Yoshizawa (2008), Steps in lithospheric thickness within eastern Australia, evidence from surface wave tomography, Tectonics, 27, TC4009, doi:10.1029/2007TC002116.

Fraser, G., S. McAvaney, N. Neumanna, M. Szpunar, and A. Reid (2010), Discovery of early Mesoarchean crust in the eastern Gawler Craton, South Australia, Precambrian Res. 179, 1-21, doi:10.1016/j.precamres. 2010.02.008.

Gunn, P. J., P. Milligan, T. Mackey, S. Liu, A. Murray, D. Maidment, and R. Haren (1997), Geophysical mapping using the national airborne and gravity datasets: An example focusing on Broken Hill, AGSO J. Aust. Geol. Geophys., 17, 127-136.

Heintz, M., and B. L. N. Kennett (2005), Seismic anisotropy beneath the Australian continent inferred from shear-wave splitting analysis, Earth Planet. Sci. Lett., 236, 106-119.

Heintz, M., and B. L. N. Kennett (2006), The apparently isotropic Australian upper mantle, Geophys. Res. Lett., 33, L15319, doi:10.1029/ 2006GL026401

Helmberger, D., and R. A. Wiggins (1971), Upper mantle structure of midwestern United States, J. Geophys. Res., 76(14), 3229-3245.

Hill, D. (1951), Geology, in Handbook of Queensland, edited by G. Mack, pp. 13-24, Aust. Assoc. for the Adv. of Sci., Brisbane, Queenls., Australia.

Kang, T.-S., and J. S. Shin (2006), Surface-wave tomography from ambient seismic noise of accelerograph networks in southern Korea, Geophys. Res. Lett., 33, L17303, doi:10.1029/2006GL027044.

Kennett, B. L. N. (2001), The Seismic Wavefield, vol. I, Introduction and Theoretical Development, Cambridge Univ. Press, New York.

Kennett, B. L. N., M. Sambridge, and P. R. Williamson (1988), Subspace methods for large scale inverse problems involving multiple parameter classes, Geophys. J. Int., 94, 237-247.

Kennett, B. L. N., K. Marson-Pidgeon, and M. S. Sambridge (2000), Seismic source characterization using a neighbourhood algorithm, Geophys. Res. Lett., 27(20), 3401-3404, doi:10.1029/2000GL011559.

Kennett, B. L. N., S. Fishwick, A. M. Reading, and N. Rawlinson (2004), Contrasts in mantle structure beneath Australia: Relation to Tasman Lines?, Aust. J. Earth Sci., 51, 563-569.

Kennett, B. L. N., M. Salmon, E. Saygin, and AusMoho Working Group (2011), AusMoho: The variation of Moho depth in Australia, Geophys. J. Int., 187, 946-958, doi:10.1111/j.1365-246X.2011.05194.x. 
Lin, F., M. P. Moschetti, and M. H. Ritzwoller (2008), Surface wave tomography of the western United States from ambient seismic noise: Rayleigh and Love wave phase velocity maps, Geophys. J. Int., 173(1), 281-298.

McLaren, S., M. Sandiford, M. Hand, N. L. Neumann, L. A. I. Wyborn, and I. Bastrakova (2003), The hot southern continent: Heat flow and hea production in Australian Proterozoic terranes, in The Evolution and Dynamics of the Australian Plate, edited by R. Hillis and D. Muller, Geol. Soc. Aust. Spec. Publ., 22, 151-161.

McLaren, S., M. Sandiford, and R. Powell (2005), Contrasting styles of Proterozoic tectonic evolution: A hot-plate model for Australian terranes, Geology, 33, 673-676.

Mojzsis, S. J., T. M. Harrison, and R. T. Pidgeon (2001), Oxygen-isotope evidence from ancient zircons for liquid water at the Earth's surface 4,300 Myr ago, Nature, 409, 178-181.

Moschetti, M. P., M. H. Ritzwoller, F. C. Lin, and Y. Yang (2010), Crustal shear velocity structure of the western US inferred from ambient noise and earthquake data, J. Geophys. Res., 115, B10306, doi:10.1029/ 2010JB007448.

Myers, J. S., R. D. Shaw, and I. M. Tyler (1996), Tectonic evolution of Proterozoic Australia, Tectonics, 15(6), 1431-1446, doi:10.1029/ 96TC02356.

Rawlinson, N., and M. Sambridge (2003), Seismic traveltime tomography of the crust and lithosphere, Adv. Geophys., 46, 81-198.

Rawlinson, N., and M. Sambridge (2004), Wavefront evolution in strongly heterogeneous layered media using the fast marching method, Geophys. J. Int., 156, 631-647.

Reading, A. M., and B. L. N. Kennett (2003), Lithospheric structure of the Pilbara Craton, Capricorn Orogen and northern Yilgarn Craton, Western Australia, from teleseismic receiver functions, Aust. J. Earth Sci., 50, 439-445.

Reading, A., B. Kennett, and M. Sambridge (2003a), Improved inversion for seismic structure using transformed, S-wavevector receiver functions: Removing the effect of the free surface, Geophys. Res. Lett., 30(19), 1981, doi:10.1029/2003GL018090.

Reading, A. M., B. L. N. Kennett, and M. C. Dentith (2003b), Seismic structure of the Yilgarn Craton, Western Australia, Aust. J. Earth Sci. 50, 427-438.

Reading, A. M., B. L. N. Kennett, and B. Goleby (2007), New constraints on the seismic structure of West Australia: Evidence for terrane stabilisation prior to the assembly of an ancient continent?, Geology, 35(4), 379-382, doi:10.1130/G23341A.1.

Sabra, K. G., P. Gerstoft, P. Roux, W. A. Kuperman, and M. C. Fehler (2005), Surface wave tomography from microseisms in Southern California, Geophys. Res. Lett., 32, L14311, doi:10.1029/2005GL023155.

Sambridge, M. (1999), Geophysical inversion with the neighbourhood algorithm: I. Searching a parameter space, Geophys. J. Int., 138 , 479-494, doi:10.1046/j.1365-246X.1999.00876.x.

Saygin, E., and B. L. N. Kennett (2010), Ambient seismic noise tomography of Australian continent, Tectonophysics, 481, 116-125, doi:10.1016/j. tecto.2008.11.013

Scheibner E., and J. J. Veevers (2000), Tasman Fold Belt System, in Billion-Year Earth History of Australia and Neighbours in Gondwanaland, edited by J. J. Veevers, pp. 154-234, GEMOC Press, Sydney, N. S. W., Australia.

Sethian, J. A., and A. M. Popovici (1999), 3-D traveltime computation using the fast marching method, Geophysics, 64, 516-523.

Shapiro, N. M., and M. Campillo (2004), Emergence of broadband Rayleigh waves from correlations of the ambient seismic noise, Geophys. Res. Lett., 31, L07614, doi:10.1029/2004GL019491.

Shapiro, N. M., M. Campillo, L. Stehly, and M. H. Ritzwoller (2005), High resolution surface wave tomography from ambient seismic noise, Science, 307, 1615-1618, doi:10.1126/science.1108339.
Shaw, R. D., P. Wellman, P. J. Gunn, A. J. Whitaker, C. Tarlowski, and M. P. Morse (1996), Guide to using the Australian crustal elements map, Aust. Geol. Surv. Organ. Rec., 1996/30, Aust. Geol. Surv. Organ., Canberra.

Simons, F. J., A. Zielhuis, and R. D. van der Hilst (1999), The deep structure of the Australian continent from surface-wave tomography, Lithos, 48, 17-43, doi:10.1016/S0024-4937(99)00041-9.

Simons, F. J., R. D. van der Hilst, J.-P. Montagner, and A. Zielhuis (2002), Multimode Rayleigh wave inversion for heterogeneity and azimuthal anisotropy of the Australian upper mantle, Geophys. J. Int., 151(3), 738-754, doi:10.1046/j.1365-246X.2002.01787.x.

Snoke, J. A., and M. Sambridge (2002), Constraints on the S wave velocity structure in a continental shield from surface wave data: Comparing linearized least squares inversion and the direct search Neighbourhood Algorithm, J. Geophys. Res., 107(B5), 2094, doi:10.1029/2001JB000498.

Stehly, L., B. Fry, M. Campillo, N. M. Shapiro, J. Guilbert, L. Boschi, and D. Giardini (2009), Tomography of the Alpine region from observations of seismic ambient noise, Geophys. J. Int., 178(1), 338-350.

van der Hilst, R., B. Kennett, D. Christie, and J. Grant (1994), Project Skippy explores the lithosphere and mantle beneath Australia, Eos Trans. $A G U, 75,177$.

Villaseñor, A., Y. Yang, M. H. Ritzwoller, and J. Gallart (2007), Ambient noise surface wave tomography of the Iberian Peninsula: Implications for shallow seismic structure, Geophys. Res. Lett., 34, L11304, doi:10.1029/2007GL030164.

Wathelet, M. (2005), Array recordings of ambient vibrations: Surface-wave inversion, Ph.D. thesis, Liège Univ., Liège, Belgium.

Wathelet, M. (2008), An improved neighborhood algorithm: Parameter conditions and dynamic scaling, Geophys. Res. Lett., 35, L09301, doi:10.1029/2008GL033256.

Woodhouse, J. H. (1974), Surface waves in a laterally varying layered structure, Geophys. J. R. Astron. Soc., 37, 461-490.

Wyborn, L. A. I., D. Wyborn, R. G. Warren, and B. J. Drummond (1992), Proterozoic granite types in Australia: Implications for lower crust composition, structure and evolution, Trans. R. Soc. Edinburgh, 83, 201-210.

Yang, Y., M. H. Ritzwoller, A. L. Levshin, and N. M. Shapiro (2007), Ambient noise Rayleigh wave tomography across Europe, Geophys. J. Int., 168(1), 259-274.

Yanovskaya, T. B. (1984), Solution of the inverse problem of seismology for laterally inhomogeneous media, Geophys. J. R. Astron. Soc., 79, 293-304, doi:10.1111/j.1365-246X.1984.tb02857.x.

Yao, H., R. D. V. der Hilst, and M. V. de Hoop (2006), Surface-wave array tomography in SE Tibet from ambient seismic noise and two-station analysis-I. Phase velocity maps, Geophys. J. Int., 166, 732-744.

Yoshizawa, K., and B. L. N. Kennett (2002), Determination of the influence zone for surface wave paths, Geophys. J. Int., 149, 440-453.

Yoshizawa, K., and B. L. N. Kennett (2004), Multimode surface wave tomography for the Australian region using a three-stage approach incorporating finite frequency effects, J. Geophys. Res., 109, B02310, doi:10.1029/2002JB002254.

Young, M., N. Rawlinson, P. Arroucau, A. M. Reading, and H. Tkalčić (2011), High-frequency ambient noise tomography of southeast Australia: New constraints on Tasmania's tectonic past, Geophys. Res. Lett., 38, L13313, doi:10.1029/2011GL047971.

Zielhuis, A., and R. van der Hilst (1996), Upper mantle shear velocity beneath eastern Australia from inversion of waveforms from Skippy portable arrays, Geophys. J. Int, 127, 1-16.

B. L. N. Kennett and E. Saygin, Research School of Earth Sciences, Australian National University, Canberra, ACT 0200, Australia. (brian. kennett@anu.edu.au; erdinc.saygin@anu.edu.au) 